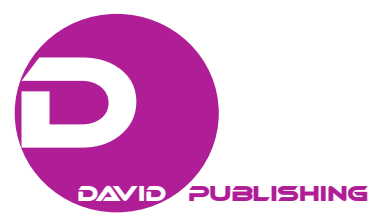

\title{
Voices From the Periphery? The Polyphony of Hip Hop and the Portuguese Community ${ }^{1}$
}

\author{
Federica Lupati \\ CHAM, FCSH, Universidade NOVA de Lisboa, Universidade dos Açores, Portugal
}

\begin{abstract}
The present work fits into a wider investigation that I have been carrying on for my project on the peculiarities of Portuguese hip hop. Through our reflections today we would like to identify some of the effects of the globalizing forces that have perturbed hip-hop culture and discuss if and how these have influenced its original purposes and messages, or the nature itself of the movement. We would also like to offer our perspective on the consequences of the entrance of hip-hop music in the international marketplace since this passage represents an important moment of its history and development and one of the strongest factors of change within this culture. We will take our examples from the Lusophone, and more specifically the Portuguese, hip hop movement, having a look at what it was in the past — or at its beginning — and at what it is today, in order to understand if we can still consider it a manifestation of peripheral voices.
\end{abstract}

Keywords: consumer culture, music market, periphery, hip hop culture, Portuguese hip hop movement

The Bronx, and more generally New York City, is widely recognized - by the media as well as the academic community - as being the birthplace of hip-hop culture. However, it is to say that hip-hop nowadays permeates the modern global society and we are witnessing an increasing globalization of what was, initially, a neighborhood based cultural practice. As a powerful subculture, therefore, in the past 40 years hip-hop has reached the most disparate areas around the globe, as well as a state of legitimation and recognition that it didn't have — and probably didn't want—when it made its appearance.

If, on one side, the opening of local and nationalistic perspectives generated a more interconnected and interdependent world with the free transfer of capital, goods, and services across national frontiers, on the other side, the clash between the homogenizing forces of financial and economic interests and the social and cultural hybridizing processes become more and more apparent. In the book Imagined Globalization-which was initially written in 1999 but translated to English in 2014-Néstor Garcia Canclini focuses on discussing how "identity is an international coproduction" (Canclini, 2014, p. 96), having in mind two main purposes: "to describe the changes on cultures in the age of globalization, and to explore alternative ways of managing it" (p. 116). By integrating metaphor and narratives through philosophically, anthropologically, and socioeconomically grounded interpretations of art, literature, media, and other forms of expression, the author

Federica Lupati, Master's degree in European, American and Postcolonial Languages and Literatures - Ca' Foscari University of Venice; PhD Candidate in Portuguese Studies and Research Assistant, CHAM, FCSH, Universidade NOVA de Lisboa, Universidade dos Açores.

Correspondence concerning this article should be addressed to Federica Lupati.

1 This paper had the support of CHAM (FCSH/NOVA-UAc), through the strategic projected sponsored by FCT (UID/HIS/04666/2013). 
arrives to the conclusion that globalization is a collection of heterogeneous narratives. Caclini also advocates that global imaginaries generate new strategies for dealing with contingencies and produce new forms of citizenship oriented towards multiple social configurations rather than homogenization.

Adapting these considerations to our field of interest, we can say that hip hop has represented since its first appearance a strategy through which the young generations overcame their condition of marginalization, becoming quickly a dystopian narrative through which a state of abandonment and the lack of opportunities could be negotiated and retransformed. By readapting musical techniques and traditions, the young DJs of the beginning of the 1970 — such as Dj Kool Herc, Grandwizzard Theodore, or Afrika Bambaata—started filling the days and the streets with beats, inviting the community to dance and rap to their rhythms, imposing new rituals of aggregation and socialization that gradually became an alternative to criminal activities and violence.

As any other cultural movement or manifestation, hip-hop wasn't designed with a specific "plan". It was just a product of the moment, a way to pass time having fun together, living the streets as meeting points where people could finally socialize peacefully. At the time, there was no political intention in the act of meeting in houses or public spaces, nor there was an artistic manifesto. Hip-hop became a new, subversive, political tool for the youths through time and space, probably thanks to its ability to represent a state of subalternity not as a passive or marginal position, but as a conscious condition of strength, where the power to resist against adversities turned into free, creative, self-expression. It soon became the narrative of the young voices, a new perspective on reality and the answer to all sorts of inequalities, a style, and a socio-political movement. And, in less than 10 years from its first appearance, it turned into a broadcasting phenomenon, becoming also a proper musical genre.

David Foster Wallace and Mark Costello suggest an interesting interpretation of rap in their book Signifying rappers: after explaining that a stereotype and a synecdoche share the same ground by referring to a part that stands for a whole, the authors note that the latter's symbolic power allows it "to absorb, comprehend and represent" (Costello \& Wallace, 2013, p. 81) the whole it belongs to, while the first one lacks of this symbolism. Hence, following the authors' argument, the power of the synecdoche depends precisely on the existence of a community that serves as a setting and a context, as well as on the presence of a public and a referent. In their words, it depends on "a world to which the Part belongs and at the same time, for its powerful dual function, that it transcends" (p. 82), and in order for this community to reach its expression it also needs to feel the external pressure of a real or imagined Other. According to the authors, it is very easy to make the mistake of interpreting rap on the basis of some poor simplifications and stereotypes, while it is actually an element of a complex network of relations that make it an even more powerful and meaningful phenomenon. In fact, we are actually in the presence of a perfect example of a synecdoche, a part that stands for a whole, the symbol of a community that reacts to the oppression of its Other.

However, nowadays, we can observe that somehow the Part has become the Whole, or even better, it has created a new Whole. Hip hop has built its own identity, amplifying its horizons and its aesthetics, charging its manifestations with political and social meanings that have been received worldwide by both performers and public. If once we could translate hip-hop as an exclusively marginal and irreverent cultural product, which claimed its peripheral position, nowadays rappers are extremely notorious public figures, who have acquired more social, economic, and cultural capital —or in other world symbolic capital (cfr. Bourdieu) - than they probably ever expected. Also, as a musical genre and product hip-hop occupies a central position worldwide, within the marketplace as well as among the most varied public. 
A good example of this, related to the Lusophone world could be taken from the opening ceremony of the Olympic games that took place on the 5th of August of this year at the Maracanã stadium in Rio de Janeiro: during this huge ceremony, the whole world had the opportunity to assist to the performance of MC Soffia and Karol Conka, two afro-Brazilian rappers and representatives of the female voices of hip hop in the country. Several observations could be made about the organizers' choice of having on stage these two performers - most of them related to some cultural issues of a different nature that characterize contemporary Brazil - but what is important to our reflection is the actual presence of hip hop as a performative act during an event broadcasted worldwide. It exemplifies quite strongly the visibility that this subculture has nowadays, its role in representing the Brazilian national identity, and how it has developed after more than three decades from its first appearance, forcing us to recognize that things have profoundly changed.

Hence, in order to better answer our questions on the relations between consumer culture and hip hop, and how its productions went from being unique, unrepeatable acts of counterculture to becoming reproducible goods, we need to understand what happened when hip hop music entered the mainstream and the marketplace.

According to the Garland Encyclopedia of World Music, "the year 1979 marks rap's music first commercial release" (Norfleet, 2001, p. 695) and the first step towards a radical change in the musical practice and production, as well as within the meanings, of hip hop: after Sugar Hill Gang's Rappers' Delight, nothing would have been the same again.

In fact, due to the expansion of the parties and events beyond what Jeff Chang calls "the Seven-Mile World" (Chang, 2005, p. 110) and the consequent growth of the public and aficionados, first the local, independent, labels, then the international ones, started "hunting" for hip hop-related artists and by the late-80s hip hop music had definitely exceeded the borders of New York's peripheries. In this general run towards success, it doesn't surprise to discover that the performers of Rappers' Delight were an improvised collective who had come together for an audition, and that they had no real connections with the actual movement happening in the ghetto nor they had any related purposes: they were probably only seeking for notoriety and diversion. As Jeff Chang explains, "when the three anonymous rappers stepped into Black indie label owner Sylvia Robinson's studio to cut 'Rapper's Delight', they had no local expectations to fulfill, no street reputations to keep, no regular audience to please, and absolutely no consequences if they failed" (Chang, 2005, p. 129). With the author's words we can say that "in retrospective, it makes perfect sense that a no-name group using partly stolen rhymes - the very definition of a crew with no style - would have been the first to tap hip hop's first platinum potential" (p. 129).

Meanwhile, the central figures of the movement refused to put their sounds into recordings. They considered unethically and basically impossible to fix into supports events that could last up to three or four hours and that were guided by improvisation and the encounter of different performative arts (such as DJing, MCing, breakdancing, and graffiti writing). Grandmaster Flash, for example, started recording later, around 1981, and his first tracks didn't really fit into the market.

Another important factor that expedited the evolution of hip hop culture from local to global is represented by the technological changes in music production. As Sarah Thornton explains, "in the 1960s, with the increased use of magnetic tapes, producers began to edit their wares into records of ideal, not real, events" (Thornton, 1995, p. 51). Furthermore, in the 1970s and 1980s new instruments were introduced, such as samples and synthesizers that allowed producing original sounds and contributed to "the shifting of the record from a secondary or derivative form to a primary, original one" (p. 51). In Thornton's opinion, the recording 
technologies did not corrode or demystify the 'aura', indeed relocating it, and to her "the mass-produced cultural commodity is not necessarily imitative or artificial, but plausibly archetypical and authentic" (p. 51).

With regards to hip hop music, technology indeed represents a decisive factor, since it made music production available to all those young artists who had no access to traditional musical instruments; it also allowed to create a dialogue between what was freshly produced (the beats) and what was circulating through the radios (disco music), making it possible for this newly-born genre to somehow insert itself into a wider cultural landscape, a very postmodern manifestation of reinventing what already existed. However, the recording of hip hop tracks and its subsequent commodification unfortunately also ended up promoting an image of its products that can be considered somehow distant from the original purposes that they had (this is, events improvised for a public of locals), also creating within the movement itself irreconcilable divergences and separations.

Historically the music industry was always a good example of what some radical theorists of capitalism such as Fernand Braudel and, later, Manuel De Landa, define as "anti-market" (the opposite of a free market), this is, a situation in which capitalists work to shut down the free circulation of commodities. In other words, what happens is that a set of institutions (the majors record companies, large commercial broadcasters, mainstream music media, among others) work hard to homogenize the tastes of an unpredictable public while smaller record labels, shops, and media outlets try to create and diversify the market whenever possible.

So, when hip hop broke into the mainstream by the mid 1980s, this is, when major music labels started picking it up because of its appeal to the youth demographic (a coveted and lucrative audience), it didn't last long before the labels quickly started popularizing more party-oriented songs and styles that were appealing to the taste of large young white audiences, leaving aside all the politically oriented songs that had attracted the producers at the beginning.

By interfacing with a broader public who didn't necessarily share the same origins and cultural roots, and having to follow the labels' directions, a new wave of artists ended up taking less risks and focusing on maximizing their incomes rather than spreading a message. As an answer to this, hip-hop products started being classified by its own creators as underground vs. commercial, and the circulation of the non-commercial tracks was deeply affected by these new perspectives. Also, a new set of categories and subgenres started to make its appearance: the old dance party-based tracks of the beginning took the name of "old school rap" (1970-1985), while the "new school rap" (1986-1990) came to represent the new, more street oriented style that preferred synthesized percussion, such as the electronic beat-box and other synthesized instruments. However, "the application of the old or new school description to rap music or its artists is by no means precise, and there is much stylistic overlapping" (Norfleet, 2001, p. 701).

The production of stereotyped and homogenized sounds, images, and messages - or at least simplified ones - created exclusively for the masses of consumers increased drastically over the years. Furthermore, hip hop artists started to commercially endorse other products, such as sneakers and clothing in general. Unfortunately, this process of commodification of hip hop music, as well of its style and attitudes ended up homogenizing the aesthetic related to the margins, the urban peripheries and the state of subalternity that reached the global public.

On the positive side, it is to mention that this commodification of hip hop also created income for many of those who had lived in precarious conditions and deprivation; it also favored the circulation of an increased 
knowledge related to youth subcultures and new strategies of resistance reached a wider public that locally appropriated them and turned them into different expressions of the reaction to a condition of marginalization.

Hence, it is precisely through audiocassettes and cinema that hip hop reached Portugal in the mid-1980s, mainly through the works of Run DMC and Public Enemy. Since its arrival it found a very receptive public, probably due to the strong similarities between the life experiences of the young inhabitants of the Bronx and the young inhabitants of the Miratejo (aka the Bronx of Portugal). In his book Ritmo e Poesia, António Concorda Contador explains that on a creative level this socio-cultural similar condition generated the most disparate forms of emulation, among which the most evident one is the constant use of what he calls "black English". This initial phase is full of references to the American hip hop, in the street style, as well as the language use. For example, the name of the first hip hop collective was B Boys Boxers, with clear reference - in English - to the art of breakdancing (Hip hop reached the Portuguese public through dance first, and then rap) and the art of beat boxing, a technique used in order to produce rhythms through the mouth substituting electronic material; furthermore, Da Weasel's first album (More than 30 Motherfxxxs) was entirely produced in English, instead of Portuguese or Cape-Verdean Creole ${ }^{2}$.

This initial lack of uniqueness and originality, however, didn't stop the movement from being characterized by a first phase that can be considered "underground": in the author's opinion Portugal works as another example of what can be considered a general tendency of hip hop culture, and this is, the fact that "everywhere it arrives, at its beginning rap is underground" (Contador, 1997, p. 165).

It didn't take long for the young Portuguese performers to contextualize their lyrics and themes, relating them to their daily life and the situations they were experiencing as afro-descendants living in Lisbon's peripheries, distancing themselves from the American expressions. As a result of this, the use of Portuguese or Creole became popular and also gained meaning as a statement of identity ${ }^{3}$.

Unfortunately, the local media didn't give much space to these manifestations and continued focusing on the products coming from the international scene, or on Portuguese music considered more "traditional". Then, it doesn't surprise to read that the first EPs of Da Weasel (More than 30 Motherf***s) and General D (Portukkkal. É um erro) were two commercial disasters and that they had no support or attention from the media or the producers.

With regards to this initial resistance, during a conversation that took place on the 27th July of this year with Rui Miguel Abreu - a broadcast journalist and writer, specialized in hip hop-I had the opportunity to discuss precisely this peculiar reaction of the Portuguese market. In Abreu's view, the initial rejection manifested by the Portuguese media is to be explained by the fact that as a musical genre, hip hop was deeply rooted in the hood. The media's refusal to promote these tracks depended on a series of negative prejudices that at the time were related to the life in the urban peripheral districts (spaces of violence, drug abuse, suspension of the law, etc.): if we take Sam the Kid (he's one of the pioneers of hip hop in Portugal), for example, we will

\footnotetext{
2 The collective Da Waesel was founded in 1993 as an experimental project entirely in English. Within the six tracks of their first EP, (God bless) Johnny is undoubtedly the most significant one, since it still represents one of their signature tracks due to its fusion between punk-rock themes and hip hop beats. However, the musical base reminds very closely of Beastie Boys' productions and doesn't really stand out for its originality, proving that Portuguese hip hop was still seeking for its own expressive strategies.

3 In order to take a closer look to the meanings of the use of Cape Verdean creole in hip hop music we suggest to refer to the very interesting studies conducted by Derek Pardue in Lisbon's periphery.
} 
notice that his tracks are deeply autobiographical and rooted in Chelas, the neighborhood where he grew up, which is also known as being infamous and disreputable. It doesn't surprise to realize that in the initial steps of his carrier he had no contact with the major labels.

The music industry in Portugal finally realized that there was actually a market for rap in Portuguese with the arrival in the radios of Gabriel "o Pensador", a Brazilian rapper who spoke directly to the Portuguese artists through the rhymes of his first album, touching some important themes such as racism, social injustice, and inequality, giving "tips" to his colleagues overseas on how to deal with these situations ${ }^{4}$. He captured the public's attention immediately. In this sense, Gabriel's concert in Lisbon in 1993 was probably the biggest hip hop gathering to ever take place in Portugal, where the entire community met and came together. This made it clear to the media that hip hop had found its space in the national cultural landscape (and market), and even if it was still living under the surface of things, it was growing in strength and consciousness, and, in other words, in public.

In line with these events and changes - during what can be seen as a phase of transition of this culture from a marginal position to a more exposed one-Sony music saw a good business opportunity and agreed to produce the collective album Rapública, which reached the markets in $1994^{5}$. Being produced in a short time and in poor conditions, the album doesn't really stand out for its beats (the rhythmical base is linear), but for its remarkable, corrosive rhymes and contents. The political purpose of the musical project was made clear by the title itself, which plays between the word "rap" and "república" as direct reference to the government, as well as the tracks Só queremos ser iguais by Zona Dread and Verdade by Boss AC, which respectively refer to the numerous episodes of racisms that took place in Portugal and to a harsh critic against the Portuguese society. Ironically, however, and despite the success of the album lies in the track Nadar by Black Company, where some superficial rhymes actually celebrate a careless attitude, the "I don't care" motto and the right to have fun ${ }^{6}$. This again proves the initial idea of the present work, this is, that unfortunately the inevitable encounter between hip hop and the marketplace does not work in favor of the first, at least at an ethical and aesthetical level.

The huge success of the track Nadar in some sense "condemned" Portuguese hip hop to being easily associated with a very non-provocative attitude, mainly produced for the public's superficial entertainment. Another example of the different role that hip hop began playing within the Portuguese society after 1994 is the track Rap da Campanha written by Dj Groove for Cavaco Silva's elections' run of 1996. Having a rap promoting a political campaign can be interpreted as: on one side, the legitimation of this musical expression as a powerful vehicle appealing to the mainstream public (the voters); on the other side, as manifestation of the complete loss of the original message and purpose and of its assimilation by the same establishment it initially fought, that Other against whom hip hop it had built its identity as a manifestation of a collective act of counterculture.

\footnotetext{
${ }^{4}$ We are referring here to the track Lavagem Cerebral (Sony, 1993).

5 Rapública represents the first rap compilation to be released in Portugal, by Portuguese artists, all based in the Margem Sul (literally the "Southern Margin": the southern districts of Lisbon's urban area). It collected 14 tracks by various artists such as Líderes da Nova Mensagem, Boss AC, Black Company, Family, New Tribe, Zona Dread, and Funky D. The tracks alternate the use of English with Creole and Portuguese, depending on the musical, cultural, and personal influences of the performers. Despite having left the musical scene today, the artists of Rapública are to be considered the real pioneers of hip hop music in Portugal.

${ }^{6}$ The track calls out most of the local hip hop artists- such as Kussundulola, Da Weasel, General D, Zona Dread, and many others - by saying that they "can't swim" (não sabe nadar) meaning that they don't know how to have fun, then celebrating parties and entertainment such as ladies and music.
} 
Therefore, we can start talking about the existence of an actual rap movement in Portugal around the mid-1990s, when the number of meeting points for hip hop performers or spaces dedicated to live battles (the most known at that time was the Johnny Guitar, in Bairro Alto), as well as hip hop acts in night clubs and radio programs (Ataque Verbal by Pacman - 1996/97), increased exponentially. In this initial phase, the year of 1995 probably represents hip hop's peak of media exposure, proved by the fact that General D and Da Waesel win the Blitz ${ }^{7}$ musical prizes of, respectively, artist of the year and band of the year (Blitz is a musical magazine founded in 1984 that between 1994 and 2001 awarded national and international artists and bands).

Yet, as it had happened in the United States, the increasing media attention and the growing of the public caused a deep scission within the Portuguese movement: the separation between underground and commercial (or "sellout") became increasingly strong and a harsh critic took place against those rappers who had signed contracts with major labels such as Sony or EMI (Mind da Gap, Black Company, Ithaka, among others): they were considered responsible for taking the entire culture way too far from where it belonged, and for letting the public decide what to say and how, instead of speaking their truth, with no ornaments, with no interest in making it perceivable by those who weren't living in their social environment. As a consequence of this scission, those who considered themselves underground rappers began performing exclusively for small, selected publics, refusing to have any contact with the market and its representatives.

Hence, if on one side this approach can be considered as in line with the original ideology of hip hop culture and its ambitions, on the other side it ended up favoring the progress of the commercial side of the movement by endorsing a closed attitude instead of thinking of a proper plan in order to spread a different message through alternative channels. However, the Portuguese case represents another example of what can be considered the general path of hip-hop culture, and this is, a path that led to its commodification.

Nowadays, 20 years after the album Rapública reached the public, some of the artists of that time are still working as performers, representing the old school generation of the Portuguese hip hop. From that initial compilation, the artist that achieved the greatest success is Boss AC: he has now five commercial releases in his name that have all reached the charts and is still performing around the country as a rapper and a $\mathrm{Dj}$. His top hit is "Hip hop (sou eu e és tu)", a sort of love letter dedicated to the musical genre, sang on a catchy beat that depicts an idealistic imagine of the entire hip hop culture. It was released in his most famous album, Ritmo, Amor e Palavras (2005). Most of artists of the time aren't active today, and other, such as Sam the Kid for example, have focused their work more on production, while continuing to perform in few occasions. However, new performers have emerged, such as Valete or Capicua. The latter is a female rapper from Porto who has managed to conciliate hip hop with the Portuguese musical tradition by integrating numerous songs from the left-wing resistance. Both artists still use their music in order to express their concerns on social issues and inequalities, despite the mainstream exposure.

Yet, what has drastically changed from the past is the medium through which rappers disclose and promote their works. Social media, particularly Youtube, have been gradually replacing the role of music labels, and today we are observing a large amount of self-promoted and self-produced artists who manage to create large groups of supporters without any help from the majors. Therefore, if on one side the above mentioned old school artists continue to be related to the old dichotomy between commercial/underground, today a new category has made its appearance thanks to the new means available, and this is, independent music: artists

\footnotetext{
7 Blitz is a musical magazine founded in 1984. Between 1994 and 2001 it annually awarded national and international artists and bands with symbolic recognition to their latest works.
} 
such Força Suprema, Loreta, the collective KBA, and Piruka, among many others, manage to reach high levels of notoriety and media exposure using their own platforms.

In this sense, it is also to mention that new sources of interesting material and information on the Portuguese movement have also appeared, such as the website Rimas $e$ Batidas founded by the above mentioned Rui Miguel Abreu: the website is entirely dedicated to the distribution of the latest works coming from the hip hop scene in Portugal, as well as abroad, and works as a useful database of updated information about the current productions.

As a conclusion to our reflections, we can say that the contact between hip hop and the commercially oriented, globalized market transformed it into a commodity that today occupies a central space within the transnational scenario. This demands that we, as researchers and academics, or simply as consumers, review and renew the postulates through which we have been defining and perceiving hip hop culture until today as a merely peripheral art and a marginalized product, since it is undeniable that its position within the market and in relation to the establishment has deeply changed and evolved.

The Portuguese case represents another example of how profoundly things have evolved since the first block parties in the Bronx. However, if, on one hand, the old ethical, aesthetical, and political purposes have made space to a wider range of themes and styles that somehow distance hip hop from being an act of counterculture and insert it in the mainstream musical productions, on the other hand, thanks to social media and to new platforms, new performers have the opportunity to manage their careers and reach high rates of followers without the support of major labels, this is, as independent artists, overcoming some of the limits and contaminations of the music market. However, based on the observation of the changes occurred and briefly presented here, we can state that the entrance of hip hop music in the market has inevitably changed its original product and if once we could consider hip hop as an exclusively marginal and irreverent cultural product, nowadays its space is central within the market and the music consumption.

\section{References}

Bourdieu, P. (1996). As regras da arte. Génese e estrutura do campo literário. Lisboa: Editorial Presença.

Canclini, N. G. (2014). Immagined globalization. Durham: Duke University Press.

Chang, J. (2005). Can't stop, won't stop: A history of the hip-hop generation. New York: St. Martin's Press.

Cidra, R. (2010). Hip hop. In S. Castelo-Branco (Ed.), Enciclopédia da música em Portugal no século XX (pp. 618-623). Lisboa: INET.

Contador, A. C. (1997). Ritmo e Poesia. Os caminhos do Rap. Lisboa: Assírio \& Alvim.

Costello, M., \& Wallace, D. F. (2013). Signifying rappers. New York: Back Bay Bookså.

Norfleet, D. M. (2001). Hip-hop and rap. (Vol. 3). In E. Koskoff (Ed.), Tha Garland Encyclopedia of World Music: The United States and Canada (pp. 692-735). New York and London: Garland Publishing Inc.

Thornton, S. (1995). Club cultures. Music, media and subcultural capital. Cambridge: Polity Press. 